\title{
Platelet-derived growth factor-induced Akt phosphorylation requires mTOR/Rictor and phospholipase $C-\gamma 1$, whereas 56 phosphorylation depends on mTOR/Raptor and phospholipase D
}

\author{
Masoud Razmara, Carl-Henrik Heldin and Johan Lennartsson*
}

\begin{abstract}
Mammalian target of rapamycin (mTOR) can be found in two multi-protein complexes, i.e. mTORC1 (containing Raptor) and mTORC2 (containing Rictor). Here, we investigated the mechanisms by which mTORC1 and mTORC2 are activated and their downstream targets in response to platelet-derived growth factor (PDGF)-BB treatment. Inhibition of phosphatidylinositol 3-kinase (PI3K) inhibited PDGF-BB activation of both mTORC1 and mTORC2. We found that in Rictor-null mouse embryonic fibroblasts, or after prolonged rapamycin treatment of NIH3T3 cells, PDGF-BB was not able to promote phosphorylation of Ser473 in the serine/threonine kinase Akt, whereas Thr308 phosphorylation was less affected, suggesting that Ser473 in Akt is phosphorylated in an mTORC2-dependent manner. This reduction in Akt phosphorylation did not influence the phosphorylation of the $\mathbf{S 6}$ protein, a well established protein downstream of mTORC1. Consistently, triciribine, an inhibitor of the Akt pathway, suppressed PDGF-BB-induced Akt phosphorylation without having any effect on S6 phosphorylation. Thus, mTORC2 does not appear to be upstream of mTORC1. We could also demonstrate that in Rictor-null cells the phosphorylation of phospholipase CY1 (PLCY1) and protein kinase C (PKC) was impaired, and the PKCa protein levels strongly reduced. Furthermore, interfering with the PLCY/Ca ${ }^{2+} / \mathrm{PKC}$ pathway inhibited PDGF-BB-induced Akt phosphorylation. In addition, PDGF-BB-induced activation of mTORC1, as measured by phosphorylation of the downstream S6 protein, was dependent on phospholipase D (PLD). It has been shown that Erk1/2 MAP-kinase directly phosphorylates and activates mTORC1; in partial agreement with this finding, we found that a Mek1/2 inhibitor delayed S6 phosphorylation in response to PDGF-BB, but it did not block it. Thus, whereas both mTORC1 and mTORC2 are activated in a PI3K-dependent manner, different additional signaling pathways are needed. mTORC1 is activated in a PLD-dependent manner and promotes phosphorylation of the $\$ 6$ protein, whereas mTORC2, in concert with PLCY signaling, promotes Akt phosphorylation.
\end{abstract}

Keywords: PDGF, PI3K, mTOR, Rictor, Raptor, Akt, PLC, PKC, PLD, S6

\section{Background}

Platelet-derived growth factor (PDGF) stimulates proliferation, migration and survival of mesenchymal cells and plays a pivotal role during embryonic development and wound healing [1]. The biologically active form of PDGF consists of disulphide-linked dimers, PDGF-AA, $-\mathrm{AB},-\mathrm{BB},-\mathrm{CC}$ and $-\mathrm{DD}$, which bind to two structurally similar tyrosine kinase receptors, i.e. PDGFR $\alpha$ and

\footnotetext{
* Correspondence: Johan.Lennartsson@LICR.uu.se

Ludwig Institute for Cancer Research, Science for life laboratory, Box 595, Biomedical Center, SE-751 24, Uppsala, Sweden
}

PDGFR $\beta$ [2,3]. PDGFR $\alpha$ binds all PDGF chains except PDGF-D, whereas PDGFR $\beta$ interacts only with PDGF $\mathrm{B}$ - and D-chains. The binding of the bivalent ligand induces dimerization and activation of PDGFRs, leading to autophosphorylation of tyrosine residues in the intracellular region [2]. Thereby, several signal transduction pathways are initiated, including phosphatidylinositol 3-kinase (PI3K), the Src tyrosine kinase, phospholipase $\mathrm{C} \gamma$ (PLC), and several mitogen-activated protein (MAP) kinase cascades.

mTOR is the mammalian ortholog of the yeast serine/ threonine kinase TOR which is involved in the regulation 
of various cellular functions, such as initiation of translation, cell growth and proliferation, ribosome biogenesis, transcription and cytoskeletal reorganization [4]. Dysregulation of mTOR signaling is frequently seen in cancer and has attracted attention as a therapeutic target $[5,6]$. mTOR is functional in two distinct complexes, namely mTORC1 and mTORC2 [7]. mTORC1 activity is controlled by the G-protein Rheb; Rheb-GTP promotes mTORC1 activity and the tuberous sclerosis complex $1 / 2$ (TSC1/2) acts as a GTPase activating protein for Rheb, consequently inhibiting mTORC1 activity [8]. Generally, mTORC1 is described as being activated by growth factors through Akt-mediated phosphorylation which inactivates the TSC1/2 complex [8-10]. In addition, the TSC1/2 complex can also be phosphorylated and inhibited by AMPK, thus allowing the cellular energy status to impact mTORC1 activity [11]. mTORC1 is a rapamycin-sensitive complex, and includes the proteins Raptor (regulatory-associated protein of mTOR), mLST8, PRAS40 and Deptor [12]. Raptor acts as a scaffold and thereby controls mTORC1 activity. Established functions for mTORC1 are to phosphorylate 4EBP1 and activate S6-kinase, which in turn phosphorylates the S6 protein [13]. Phosphorylated S6 and 4EBP1 enhance protein translation. In mTORC2, mTOR occurs in a complex with Rictor (rapamycininsensitive companion of mTOR), mLST8, $\mathrm{mSin} 1$, protor, Deptor and Hsp70 [14-17]. mTORC2 is primarily activated by growth factors, but the mechanism is largely unknown. It has recently been suggested that mTORC2 activation is dependent on PI3-kinase, but independent of Akt [18]. mTORC2 is able to phosphorylate Akt on Ser473, at least in some cell types [19]. Other substrates for mTORC2 include PKC $\alpha$ and paxillin [20]. mTOR can be activated by growth factor signaling, such as by PDGF, but the roles of mTORC1 and mTORC2 in PDGF-BBinduced signal transduction have not been established.

The serine/threonine kinase Akt is activated by PDGFBB stimulation in a PI3-kinase-dependent manner. Activation of PI3-kinase generates $\mathrm{PIP}_{3}$ that can interact with and thereby translocate Akt to the plasma membrane, where it is activated by phosphorylation on Ser473 in a hydrophobic motif and Thr308 in the activation loop of the kinase domain [19,21,22]. Thr308 is phosphorylated by phosphoinositide-dependent protein kinase 1 (PDK1), whereas several candidates, including mTORC2, may perform the Ser473 phosphorylation [19,23-25]. Furthermore, the kinase responsible for the Ser473 phosphorylation may be different for different cell and receptor types. When activated, Akt transduces important survival signals that interfere with the apoptotic process, for example by inhibition of Foxo, Bad and caspase 9 [26-28].

Phoshoplipase $\mathrm{C} \gamma$ catalyzes the hydrolysis of $\mathrm{PIP}_{2}$, thus releasing the polar head group inositol-1,4,5-trisphosphate
$\left(\mathrm{IP}_{3}\right)$, while diacylglycerol (DAG) remains embedded in the plasma membrane [29]. $\mathrm{IP}_{3}$ release results in mobilization of $\mathrm{Ca}^{2+}$ from intracellular stores. Both DAG and $\mathrm{Ca}^{2+}$ participate in the activation of protein kinase $\mathrm{C}$ (PKC) family members, some of which require both DAG and $\mathrm{Ca}^{2+}$ (PKC $\alpha, \beta, \gamma)$, whereas others require only DAG (PKC $\delta, \varepsilon$, $\eta, \theta)$ [30]. In addition, there are atypical PKC isoforms (PKC, $\mathrm{l}$ ) that are regulated by other means [31]. PLC $\gamma$ is activated by direct $\mathrm{SH} 2$-domain-dependent interaction with activated tyrosine kinase receptors and subsequent phosphorylation [32,33]. Another phospholipase that is activated by receptor tyrosine kinases is phospholipase D (PLD). PLD acts by hydrolyzing phosphatidylcholine generating choline and phosphatidic acid [34] which is required for mTORC1 activation by mitogenic factors [35]. Regulation of PLD activity is complex and has been shown to involve small G-proteins, phosphatidylinositol 4,5-bisphosphate $\left(\mathrm{PIP}_{2}\right), \mathrm{Ca}^{2+}$ and kinases [36]. PDGF has been demonstrated to promote PLD tyrosine phosphorylation and activation by a mechanism involving the production of reactive oxygen species [37].

In this study, we have explored the role of mTOR in the regulation of PDGF-BB signaling. We found that Rictor, and hence mTORC2, promotes the PDGF-BB-induced phosphorylation of Akt at Ser473, as well as the phosphorylation of PLC $\gamma 1$ and $\mathrm{PKC} \alpha$ in addition to promoting PKC $\alpha$ protein stability. Moreover, we show that PLD activity is important for S6 phosphorylation and that this occurs through mTORC1. However, our data suggest that S6 phosphorylation downstream of PDGFR does not rely on Akt activation. Functionally, mTOR inhibition by rapamycin suppressed PDGF-BB-mediated cell proliferation, whereas rapamycin treatment or the loss of Rictor in the mTORC2 complex had no significant impact on the chemotactic response toward PDGF-BB.

\section{Results}

Inhibition of mTORC2-Akt signaling does not influence the phosphorylation of the ribosomal S6 protein downstream of mTORC1

Initially, we investigated if mTORC1 and mTORC2 function downstream of PI3K using the selective pan PI3K inhibitor NVP-BKM120, which in contrast to the classical PI3K inhibitors wortmannin or LY29004 does not inhibit mTOR [38]. NPV-BKM120 inhibited Akt phosphorylation at both Ser473 and Thr308 and also reduced mTOR and $\mathrm{S6}$ phosphorylation upon PDGF-BB stimulation (Figure 1A), indicating that PI3K is required for activation of both mTOR complexes.

Previous studies have shown that Rictor is an essential component of the mTORC2 complex, which induces Akt phosphorylation at Ser473, at least in some cell types [39]. To elucidate whether mTORC2 is also necessary for PDGF-BB-induced Akt phosphorylation in 


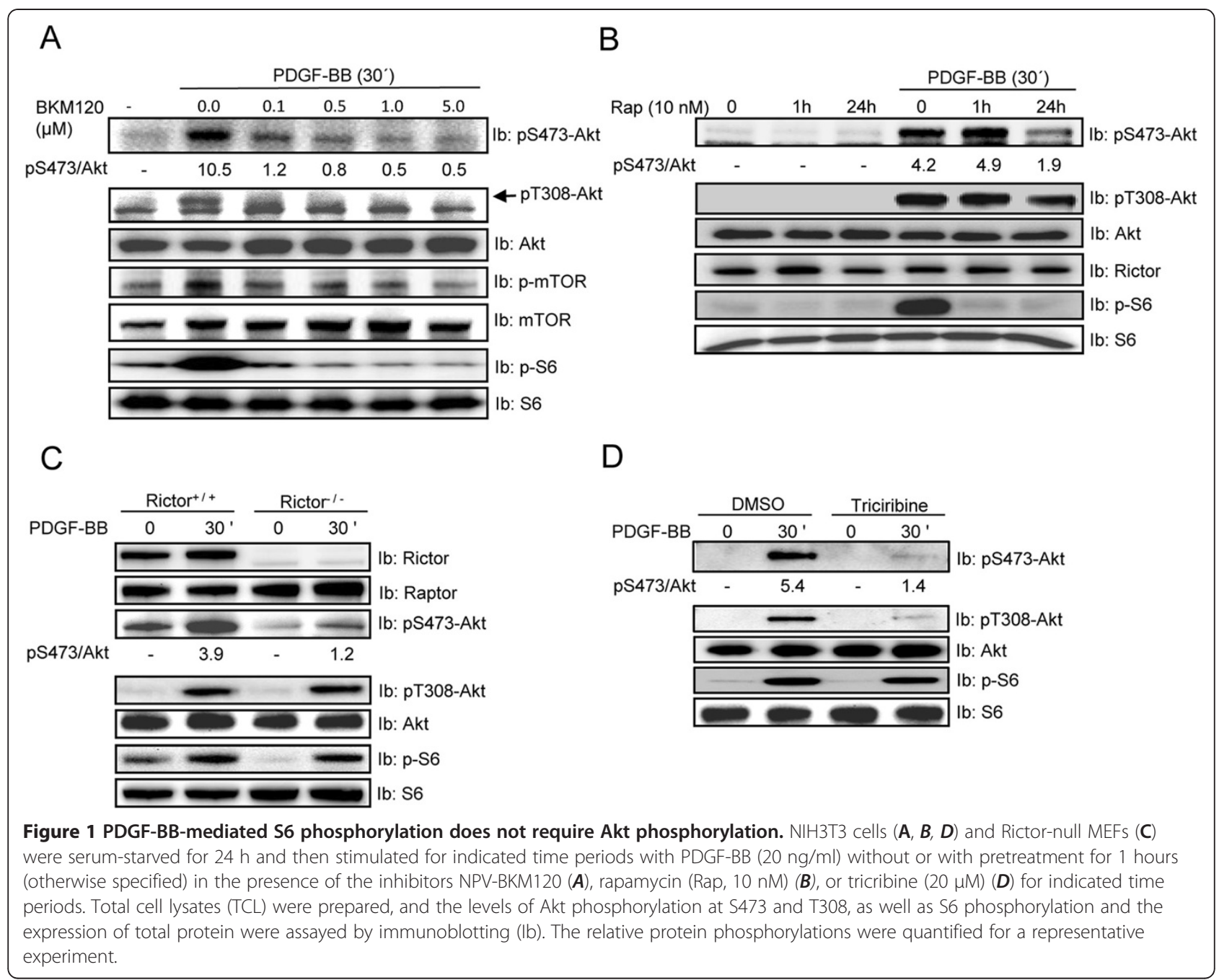

fibroblasts, we used prolonged rapamycin treatment of NIH3T3 cells, which has been shown to inhibit mTORC1 and 2, as well as Rictor-deficient cells. Using both approaches, mTORC2 was found to be important for PDGF-BB-induced phosphorylation of Akt on Ser473, but not on Thr308 (Figure 1B \& C), although prolonged rapamycin treatment slightly reduced Thr308 phosphorylation. In contrast, a short term treatment with rapamycin, which only inhibits mTORC1, did not influence the PDGF-BBinduced Akt phosphorylation (Figure 1B). However, the levels of Rictor were not affected by rapamycin treatment (Figure 1B).

There are reports suggesting that mTORC2-Akt can be considered as upstream regulator of mTORC1 and its downstream substrate S6 [40-42]. We investigated whether this is the case using Rictor-null cells. As can be seen in Figure $1 C$, no decrease in the PDGF-BB-induced S6 phosphorylation is seen in Rictor-deficient cells compared to control cells, suggesting that mTORC2-Akt is not upstream of mTORC1-S6. In contrast, both short term treatment with rapamycin (inhibits mTORC1), or long term treatment (inhibits both mTORC1 and 2) efficiently inhibited S6 phosphorylation, confirming the importance of mTORC1 for its phosphorylation (Figure 1B). To further confirm that Akt is not needed for S6 phosphorylation, we used the Akt pathway inhibitor triciribine [43]. Triciribine completely abolished the PDGF-BB-induced Akt phosphorylation, but did not influence S6 phosphorylation (Figure 1D).

To conclude, mTORC2 is of major importance for Akt Ser473 phosphorylation and the mTORC1-promoted phosphorylation of $\mathrm{S} 6$ is not dependent on signaling through the mTORC2-Akt pathway.

\section{mTORC1-mediated phosphorylation of S6 depends on PLD}

PLD has been proposed to contribute to mTORC1 activity by producing phosphatidic acid (PA) [35]. To investigate the importance of PLD in the activation of mTORC1 and 2 , we treated cells with 1-butanol which is a preferred 
substrate for PLD [44], thus reducing the production of PA. The secondary alcohol, 2-butanol, was used as a negative control since PLD cannot use it as a substrate. As shown in Figure 2A, the ability of PDGF-BB to promote phosphorylation of the mTORC1 substrate S6 was reduced in the presence of 1-butanol, but not in the presence of 2-butanol. Importantly, phosphorylation of Akt, which is dependent on mTORC2, was not reduced by 1-butanol treatment (Figure 2A). Similar to NIH3T3 cells, we also found that the 1-butanol treatment attenuates S6 phosphorylation in Rictor null MEFs (Figure 1C).

Since PDGF-BB induces both $\mathrm{Ca}^{2+}$ influx and intracellular $\mathrm{Ca}^{2+}$ release [45], and it has been shown that $\mathrm{Ca}^{2+}$ can regulate PLD activation [46], we investigated the impact of $\mathrm{Ca}^{2+}$ chelators on PDGF-BB-induced S6 and Akt phosphorylation. We found that chelation of extracellular or intracellular $\mathrm{Ca}^{2+}$ by EDTA and BAPTA, respectively, both efficiently inhibited the phosphorylation of S6 consistent with a role for $\mathrm{Ca}^{2+}$ in PLD activation or subsequent mTORC1 activation (Figure 2B). Interestingly, we also observed that the PDGF-BB-induced Akt phosphorylation on Ser473 was inhibited by $\mathrm{Ca}^{2+}$ chelation (Figure $2 \mathrm{~B}$ ).

In summary, these finding indicate that PLD signaling is necessary for PDGF-BB-induced phosphorylation of S6 by mTORC1, and that $\mathrm{Ca}^{2+}$ is central for Akt phosphorylation on Ser473 in response to PDGF-BB.

\section{PLC signaling is important for PDGF-BB-induced Akt phosphorylation}

To confirm our finding that $\mathrm{Ca}^{2+}$ is involved in regulation of Akt phosphorylation on Ser473, we used dominant negative PLCy (dnPLC $\gamma$ ), and the low molecular weight inhibitor U73122, which inhibits both PLCY and PLD $[47,48]$. Consistent with the effect of $\mathrm{Ca}^{2+}$ chelation (Figure 2B), U73122, as well as dnPLC $\gamma$ inhibited Ser473 phosphorylation on Akt, however, no effect on the phosphorylation of Thr308 was found (Figure 3A \& B). In addition, U73122 also inhibited S6 phosphorylation, in concurrence with the ability of this drug to inhibit PLD. To further investigate the role of PLC $\gamma$ signaling in Akt activation, we used PLC $\gamma 1$-null cells. Importantly, these cells have been shown to also have a deficient PLD activation [49]. Using these cells, we observed a defect in PDGF-BB-induced Akt phosphorylation on Ser473, but also on Thr308 (Figure 3C). This surprising finding suggests that phosphorylation of Akt on Ser473 is dependent on PLC $\gamma$ activity, whereas the phosphorylation on Thr308, which is not affected by PLC inhibition or $\mathrm{Ca}^{2+}$ chelation, requires the presence of PLCy1, but not necessarily its activity. Previously, it has been shown that inhibition of p38 signaling by SB203580 reduces Akt phosphorylation [50]. This effect was not observed in our experiment (Figure 3A).

Since PKC isoforms are activated downstream of $\mathrm{PLC} \gamma$, and it has been reported that $\mathrm{mTORC} 2$ regulates the stability and phosphorylation of PKCa [51], we investigated if the requirement of $\mathrm{Ca}^{2+}$ and $\mathrm{PLC \gamma}$ for Akt phosphorylation occurred through activation of PKC. First, we confirmed the previously reported reduction of PKC $\alpha$ levels in the Rictor-null cells (Figure 3D). Next, we downregulated the PKC isoforms that are dependent on diacylglycerol (DAG) for their activation, by treating cells with PMA overnight. To monitor the effect of PMA treatment, we investigated phosphorylation of

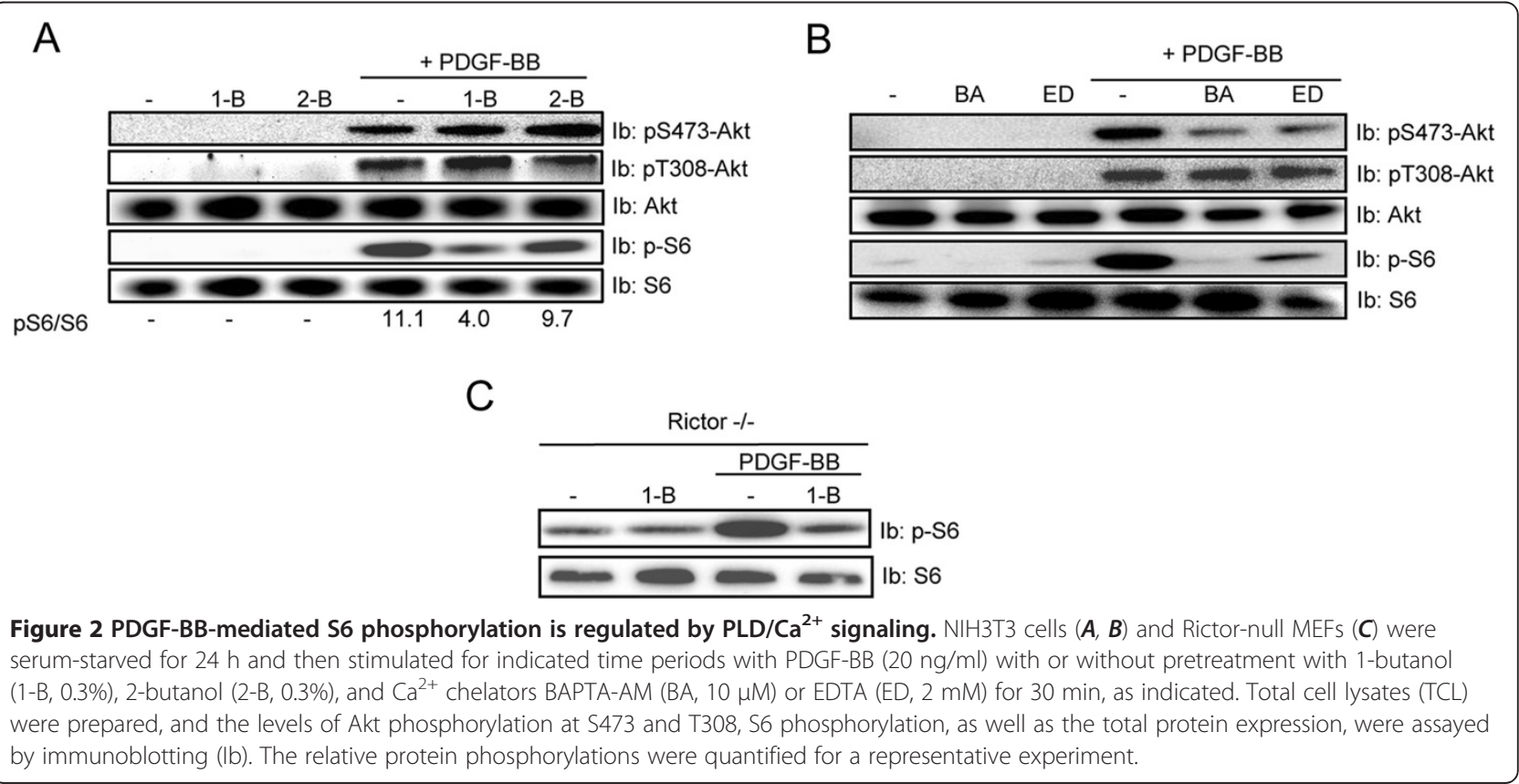




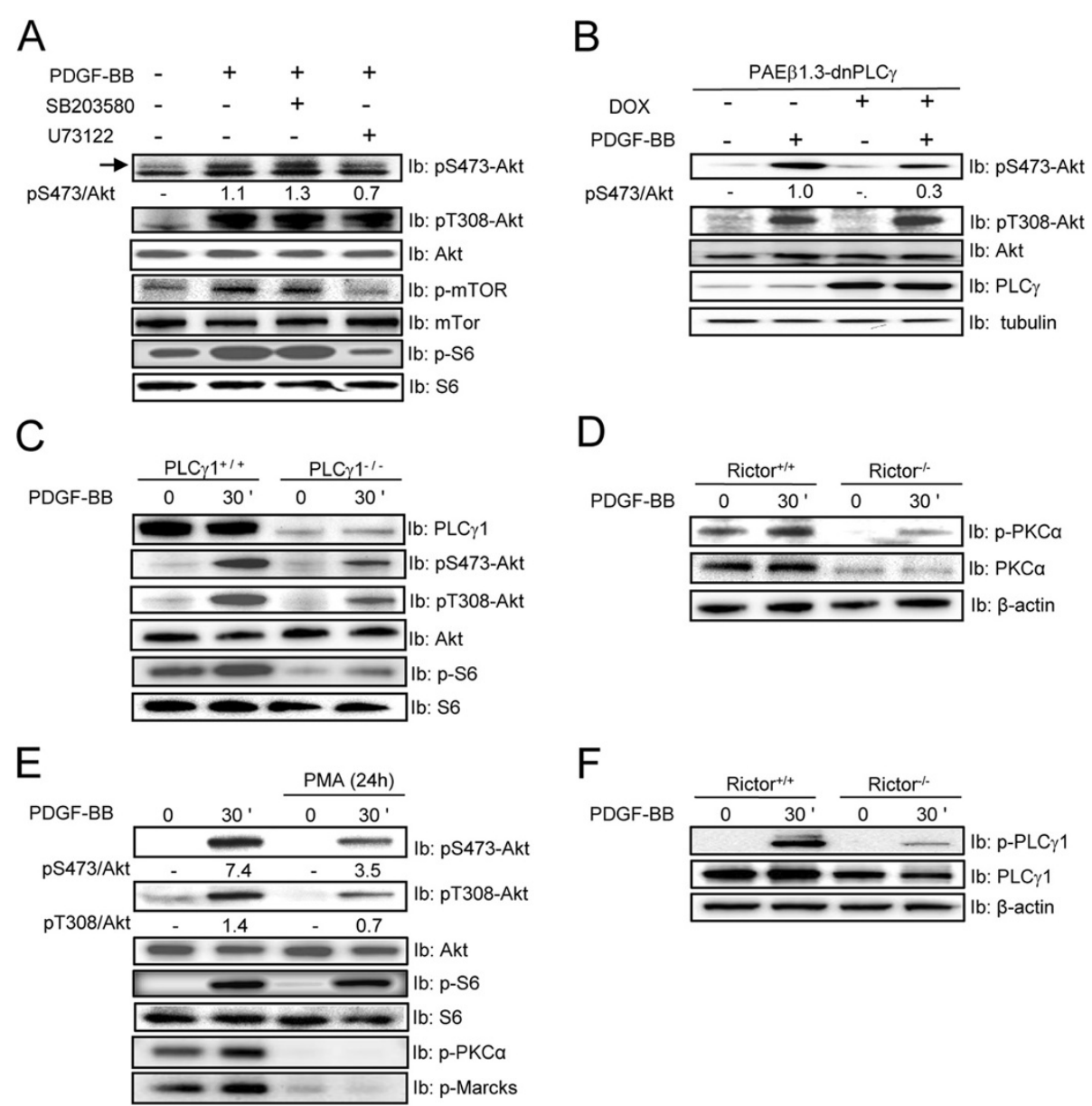

Figure 3 PDGF-BB-induced Akt phosphorylation involves the PLC/PKC pathway. NIH3T3 cells $(\boldsymbol{A}$ and $\boldsymbol{E})$, dnPLCY PAE cells $(\boldsymbol{B})$, PLCY-null $(\boldsymbol{C})$ and Rictor null ( $\boldsymbol{D}$ and $\boldsymbol{F})$ MEFs were serum-starved for $24 \mathrm{~h}$ and then stimulated with PDGF-BB $(20 \mathrm{ng} / \mathrm{ml})$ with or without pretreatment with the

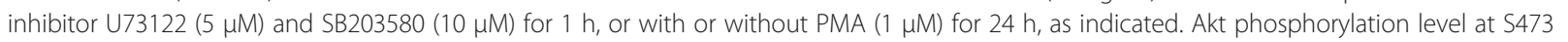
and T308, as well as mTOR, S6, PLCY, PKCa and pMarcks phsphorylation and the total protein expression were assayed by immunoblotting (Ib) of total cell lysate. $\beta$-actin immunoblotting served as a loading control. The relative protein phosphorylations were quantified for a representative experiment.

Myristoylated Alanine-Rich C-Kinase (MARCKS), a known PKC substrate (Figure 3E). In cells with downregulated PKC isoforms, we observed a partial reduction in the ability of PDGF-BB to promote Akt phosphorylation (Figure 3E). Consistent with our previous experiments, we found that S6 phosphorylation was independent of the reduction in Akt phosphorylation (Figure 3E).

The activity of PLCY has been connected to its phosphorylation on Tyr783 [52]. To see if the absence of Rictor (and thus mTORC2) affects PLCY function, we analyzed the ability of PDGF-BB to stimulate PLCY phosphorylation. Surprisingly, we found that in Rictornull cells the PLC $\gamma$ phosphorylation was abolished and similar to what was seen for $\mathrm{PKC} \alpha$, the total protein level was slightly reduced (Figure 3F). The mechanism for the reduced $\mathrm{PLC} Y$ protein level is unclear, but in the case of $\mathrm{PKC} \alpha$ it has been demonstrated that mTOR- mediated phosphorylation is important for protein stability [53].

To conclude, inhibition of PLCy or $\mathrm{Ca}^{2+}$ chelation resulted in decreased PDGF-BB-induced phosphorylation of Akt on Ser473, but did not affect phosphorylation on Thr308. In contrast, the presence of PLCY protein was needed for the phosphorylation on Thr308. Furthermore, we found that Rictor-null cells, which have defective PDGF-BB-induced Akt Ser473 phosphorylation, are impaired in PLC $\gamma / \mathrm{PKC} \alpha$ signaling. However, treatment overnight with PMA inhibited Akt phosphorylation on both Ser473 and Thr308. These findings suggest that Thr308 is phosphorylated by a kinase that is downregulated by PMA treatment and thus normally regulated by DAG, possibly a novel PKC isoforms that requires DAG but not $\mathrm{Ca}^{2+}$. Overnight treatment with PMA did not affect PDK-1 phosphorylation and neither 
did PDGF-BB treatment (data not shown). In contrast, phosphorylation of Akt on Ser473 is dependent on PLC $\gamma 1$ activity, $\mathrm{Ca}^{2+}$, DAG and the conventional PKCs.

\section{PDGF-BB-induced Erk1/2 MAP-kinase signaling is} important for the kinetics of S6 phosphorylation In addition to Akt, MAP kinase pathways have been linked to mTOR signaling [54]. We found that the selective Mek1/2 inhibitor CI-1040 completely blocked Erk1/2 phosphorylation and reduced S6 phosphorylation, primarily after $15 \mathrm{~min}$ of stimulation, but had no effect on Akt phosphorylation (Figure 4A). Thus, Erk1/2 may contribute to mTORC1 activation at early stages of signaling, as previously noted [54]. To further clarify the role of Erk1/2 in mTORC1 signaling after prolonged PDGF-BB treatment, we performed a time-course experiment stimulating cells for up to $4 \mathrm{~h}$ (Figure 4B). We found that only the rapid, initial induction of S6 phosphorylation was inhibited by CI-1040, whereas the S6 phosphorylation reached almost the same level in cells treated with CI-1040 as in vehicle treated cells after longer time periods of PDGF-BB stimulation (Figure 4B). The PDGF-BB-induced Erk1/2 phosphorylation was not dependent on mTORC2 (Figure 4C), mTORC1

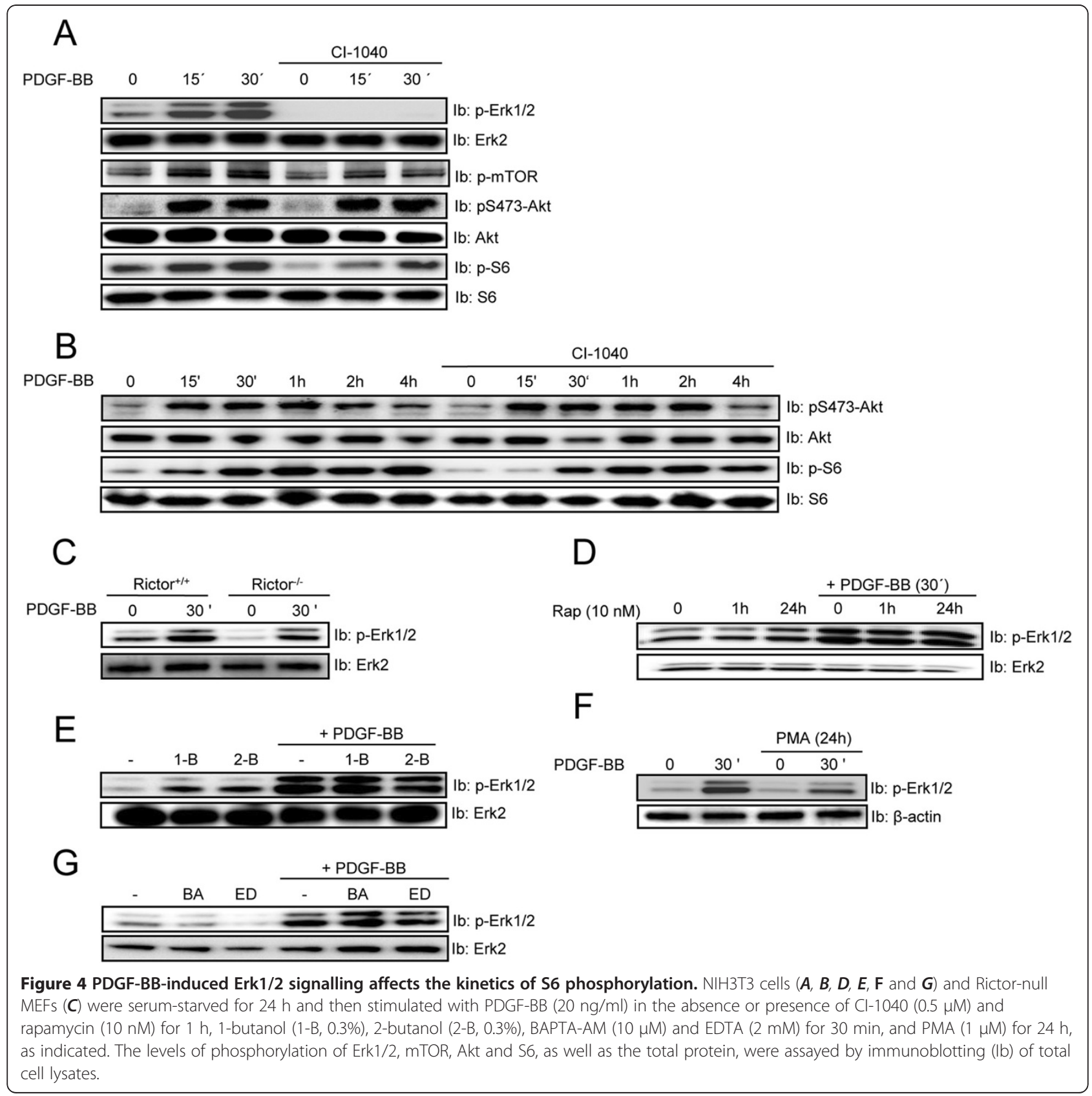


(Figure 4D \& E), PKCs (Figure 4F), or the presence of $\mathrm{Ca}^{2+}$ (Figure 4G).

In summary, PDGF-BB-induced Erk $1 / 2$ activity is only important for the early onset of mTORC1-mediated phosphorylation of S6. Furthermore, neither mTORC1 nor mTORC2 are needed for PDGF-BB-induced Erk1/2 activation.

\section{Role of mTOR signaling in PDGF-BB-induced cellular responses}

Next, we wanted to elucidate the functional consequences of interfering with mTOR signaling for PDGFBB-mediated cellular responses, i.e. survival, migration and proliferation. To this end, we used the Rictor-null cells which lack a functional mTORC2 complex, as well as long term treatment $(24 \mathrm{~h})$ with rapamycin to inhibit both mTORC1 and 2. We found that serum starvation induced caspase- 3 cleavage, which could be rescued by addition of PDGF-BB in control cells, but not in Rictor null cells, suggesting a role of mTORC2 in promoting cell survival in response to PDGF-BB (Figure 5A). In accordance with a recent report [55] we could confirm that Rictor-null cells have increased rate of apoptosis compared to control MEFs (Figure 5B). Interestingly, in these cells the apoptosis could not be modulated by either serum levels or addition of PDGF, despite the reduction of caspase 3 cleavage observed in control MEFs in the presence of PDGF. The reasons of these findings remain to be elucidated.

In contrast, the migratory response was not affected by loss of the mTORC2 complex (Figure $5 \mathrm{C}$ ). As expected, downregulation of both mTORC1 and 2 by rapamycin strongly inhibited PDGF-BB-promoted DNA synthesis in NIH3T3 cells (Figure 5D). Unfortunately, we were not able to analyze the proliferation of Rictornull cells in response to PDGF-BB, since neither control nor knock-out cells responded to PDGF-BB in the proliferation assay (data not shown). Furthermore, long term treatment with rapamycin did not affect the PDGF-BBinduced migration of NIH3T3 cells (Figure 5E).

In conclusion, PDGF-BB signaling through mTORC2 is important for the ability of PDGF-BB to suppress starvation-induced cleavage of caspase 3 , but not for chemotaxis. Complete inhibition of mTOR signaling by rapamycin abolished the ability of PDGF-BB to promote cell proliferation.

\section{Discussion}

Akt is an important kinase mediating survival signaling, which is regulated by phosphorylation on Thr308 by PDK1 and on Ser473 by several other kinases. A large number of kinases have been proposed to perform the Ser473 phosphorylation [56]. In the present study, we showed that phosphorylation of Akt on Ser473 in response to PDGF-BB was critically dependent on the mTORC2 complex since the phosphorylation was strongly repressed in Rictor-null cells. Consistently, prolonged treatment with rapamycin that downregulates both mTORC1 and 2, inhibited the PDGF-BB-induced phosphorylation on Ser473, whereas short term rapamycin treatment which only inhibits mTORC1, did not. Furthermore, we also found that U73122, which blocks both PLC and PLD activities, as well as $\mathrm{Ca}^{2+}$ chelating agents, inhibited the PDGF-BB-mediated phosphorylation of Akt on Ser473, but not on Thr308. It has been reported, and we confirmed, that in Rictor-null cells the level of PKC $\alpha$ is severely reduced [51]. In addition, we found that PLCY phosphorylation is dramatically suppressed in Rictor null cells compared to control cells. Interestingly, treatment with PMA overnight to downregulate DAG-dependent $\mathrm{PKC}$ isoforms resulted in inhibition of phosphorylation of Akt on both Ser473 and Thr308. The effect on Thr308 did not occur by any reduction in p-PDK1 levels, indicating that a DAG responsive kinase is involved in the phosphorylation of Thr308. Another possibility is that while PMA treatment overnight did not affect the phosphorylation of PDK1, it may have influenced its intracellular localization. We also found that in PLC $\gamma 1$ null cells, the phosphorylation of both Ser473 and Thr308 on Akt were reduced. Interestingly, it has recently been demonstrated that PDK1 and PLCY interact after EGF stimulation and that PDK1 is involved in the activation of PLC $\gamma$ in a manner that only partially depends on PDK1 activity [57]. Thus, it is possible that the interaction between PDK1 and PLC $\gamma$ regulates the ability of PDK1 to phosphorylate Akt on Thr308, potentially by acting as a scaffold. This hypothesis is consistent with our observation that PDGFBB-induced Thr308 phosphorylation is reduced in PLC $\gamma$ deficient cells but is not affected by PLCY inhibition or $\mathrm{Ca}^{2+}$ chelation.

Collectively, these results suggest that the pathway leading from the PDGFR to phosphorylation of Akt involves mTORC2 and $\mathrm{PLC} / \mathrm{Ca}^{2+}$ signaling, although some aspects of the molecular mechanism remain to be elucidated. Activation of Akt has been associated with increased cell viability [58]. Consistent with a critical role for mTORC2 in Akt activation, we found that in Rictor-deficient cells, which are blunted in their ability to activate Akt, PDGF-BB was not able to suppress starvation-induced caspase-3 cleavage, whereas it did so in control cells.

mTORC1 is widely accepted to be responsible for S6-kinase activation leading to phosphorylation of the ribosomal S6 protein, thus facilitating protein translation. Several reports have suggested that mTORC1 may be downstream of Akt signaling [13], although this has been challenged [59]. Our results suggest that in PDGFBB-stimulated fibroblasts, Akt is not upstream of S6 


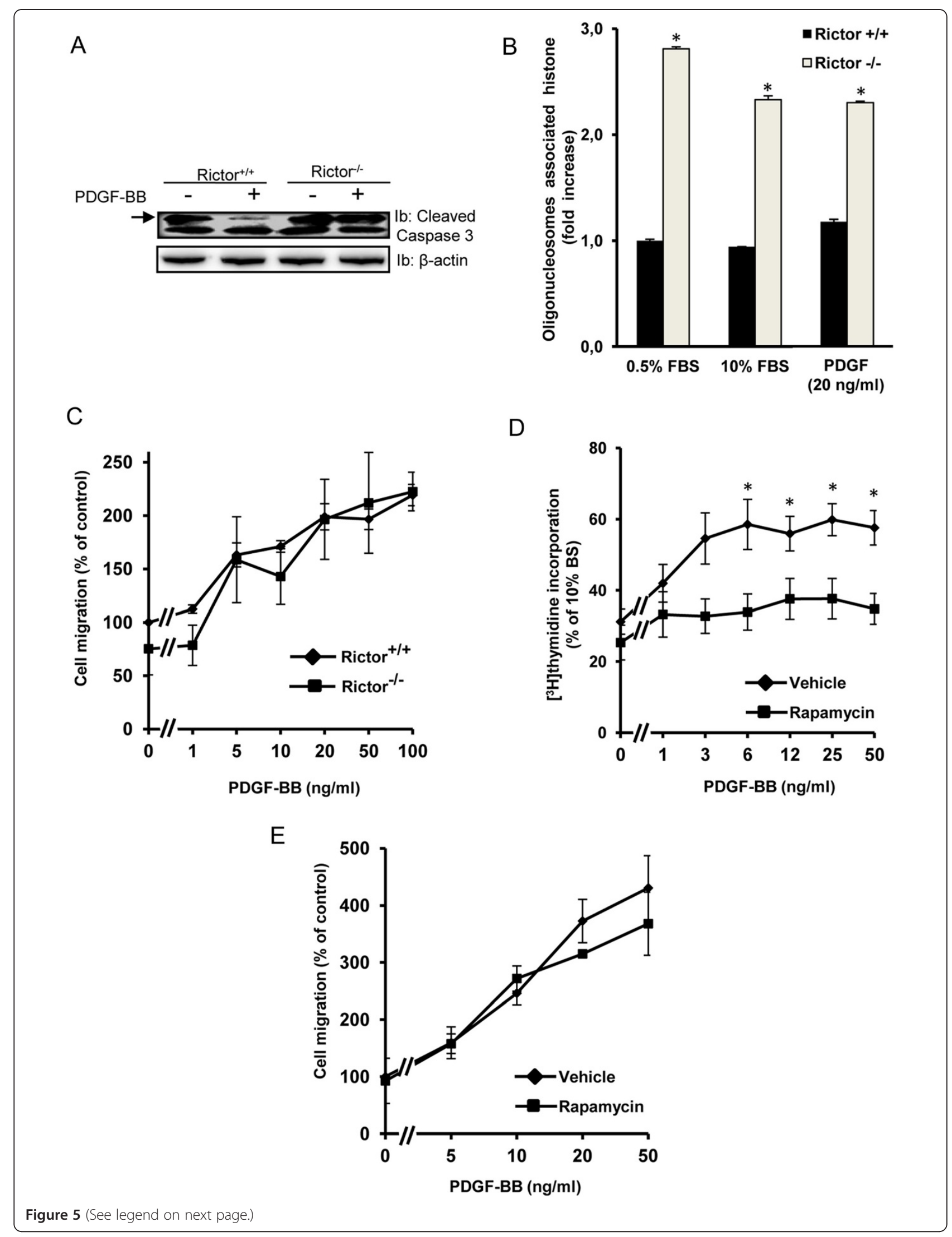




\section{(See figure on previous page.)}

Figure 5 Effect of mTOR signaling on caspase 3 cleavage, apoptosis, migration and proliferation upon PDGF-BB stimulation. Rictor-null or control MEFs were serum-starved for $24 \mathrm{~h}$ and then treated with PDGF-BB for $24 \mathrm{~h}$; activation of caspase 3 was measured thereafter by immunoblotting against cleaved caspase $3(\boldsymbol{A})$. Internucleosomal DNA fragmentation was quantitatively determined by assaying for cytoplasmic mononucleosome- and oligonucleosome-associated histone accumulated in apoptotic cell (B), data represent three separate experiments each performed in duplicate \pm SEM. Cell migration experiments were carried out in a 96-well ChemoTX cell migration microplate. The wells of the microplate were filled with medium containing combinations of PDGF-BB with Rictor-null or control MEFs (C), as well as NIH3T3 cells with or without longterm treatment with rapamycin $(\boldsymbol{E})$, as indicated. The amounts of migrated cells are given as index units; data represent three separate experiments, each performed in quadruplicates \pm SEM. In separate experiments, NIH3T3 cells were serum-starved and then stimulated for $24 \mathrm{~h}$ with PDGF-BB in medium containing $\left[{ }^{3} \mathrm{H}\right]$ thymidine. The fold increase of PDGF-induced $\left[{ }^{3} \mathrm{H}\right]$ thymidine incorporation over the respective positive control values is shown. Values are means \pm S.E of three independent experiments each performed in triplicate. Statistical significant differences (Students T-test) are indicated by ${ }^{*} P<.05$ compared with unstimulated or control cells $(\boldsymbol{B} \& \boldsymbol{D})$.

phosphorylation; for example, in Rictor-null cells, where Akt phosphorylation on Ser473 is reduced, S6 phosphorylation was normal. Moreover, treating cells with the Akt pathway inhibitor triciribine completely abolished Akt phosphorylation, but had no impact on PDGF-BB promoted S6 phosphorylation. This is consistent with a study in Drosophila showing that Akt phosphorylation of TSC2 is not required for mTOR activation [60], but in contrast to studies on insulin signaling, where it was shown that Akt phosphorylation of TSC2 is necessary for mTORC1 activation [9].

We observed inhibition of S6 phosphorylation after treatment with $\mathrm{Ca}^{2+}$ chelators. A possible $\mathrm{Ca}^{2+}$-dependent pathway from the PDGFR to mTORC1 involves PLD. PLD degrades phosphatidylcholine into choline and phosphatidic acid. Phosphatidic acid have been shown to bind to mTOR and activate mTORC1 [35]. Treatment of cells with the PLD inhibitor 1-butanol suppressed the PDGF-BBinduced S6 phosphorylation, without affecting Akt phosphorylation. As expected, the PLC/PLD inhibitor U73122 also suppressed S6 phosphorylation. It is possible that PLC $\gamma$ contributes to PLD activation by causing increased $\mathrm{Ca}^{2+}$ levels, since PLD requires $\mathrm{Ca}^{2+}$ for its activity [61]. In support of this notion, it has been reported that in PLCYdeficient cells, PLD signaling is reduced and this may explain the observed reduction in S6 phosphorylation in PLC $\gamma 1^{-1-}$ cells. Analogous to Akt activation where both mTORC2 and PDK1 phosphorylation are required for full Akt activation, mTORC1 has been proposed to collaborate with PDK1 in S6 kinase activation [62].

Erk1/2 MAP-kinases are activated by most receptor tyrosine kinases and have been shown to regulate proliferation as well as protein translation [63]. mTOR is also involved in these processes, and there are reports implicating a link between Erk1/2 and mTOR signaling. In particular, it has been shown that Erk1/2 can directly phosphorylate Raptor and as a consequence activate mTORC1 [64]. In addition, both Erk $1 / 2$ and the downstream p90 ribosomal S6 kinase can phosphorylate the TSC1/2 complex resulting in mTORC1 activation [65]. To explore whether Erk $1 / 2$ is involved in PDGF-BBinduced mTOR signaling, we investigated the effect of the selective MEK1/2 inhibitor CI-1040 on Akt and S6 phosphorylation. Inhibition of the Erk1/2 pathway did not influence the PDGF-BB-induced phosphorylation of Akt, however, it delayed the onset of S6 phosphorylation. Conversely, interfering with mTOR signaling did not significantly affect the PDGF-BB-induced Erk1/2 phosphorylation. Thus, signaling through the Erk1/2 pathway is not critical for mTORC2 activity, but is required for the initial rapid onset of mTORC1. The S6 phosphorylation observed after prolonged PDGF-BB treatment was not dependent on Erk1/2 signaling. Furthermore, it has been proposed that inhibition of mTOR-dependent signaling by rapamycin leads to an increased Erk $1 / 2$ activity and potentiation of PDGF-induced Erk1/2 phosphorylation [66]. In contrast to these findings, we observed that neither interfering with mTOR signaling using Rictor-null cells, short or long term treatment of NIH3T3 cells with rapamycin and PLD inhibition, nor $\mathrm{Ca}^{2+}$ chelation affected PDGF-BB-induced Erk1/2 phosphorylation.

Signaling through mTOR has been reported to regulate both proliferation and migration [13,67]. A commonly used inhibitor of mTOR is rapamycin. However, the two mTOR containing complexes, mTORC1 and mTORC2, have different sensitivities to rapamycin. mTORC1 is rapidly inhibited whereas $\mathrm{mTORC} 2$ requires prolonged rapamycin treatment; thus, short term $(1 \mathrm{~h})$ treatment with rapamycin only inhibits $\mathrm{mTORC} 1$ whereas long term $(24 \mathrm{~h})$ treatment also inhibit mTORC2. Treating cells for extended time periods with rapamycin abolished the mitogenic effect of PDGF-BB, suggesting that functional mTOR signaling is required for cell proliferation. In contrast, Rictor-deficient cells showed a similar chemotactic response as control cells towards PDGF-BB, indicating that mTORC2 is not involved in PDGF-BB-dependent cell migration; this is surprising since mTORC2 has been shown to regulate cell polarity and the dynamics of the actin cytoskeleton [68], although no alterations in the actin cytoskeleton were observed in Rictor-null MEFs $[51,59]$. Similarly, inhibition of mTORC1 and 2 in NIH3T3 cells did not influence the chemotactic properties of these cells. mTORC2 may affect cell migration by promoting PKC $\alpha$-dependent phosphorylation of the focal 
adhesion component paxillin [20]. However, it has previously been found that PDGF-BB can promote paxillin phosphorylation through the JNK MAP kinase pathway [69], and this may relieve the absolute requirement of mTORC2 in PDGF-BB-mediated fibroblast migration.

\section{Conclusions}

The pathway from PDGFR leading to phosphorylation of Akt involves both the mTORC2 and PLC $/ \mathrm{PKC}$ pathways. In contrast, phosphorylation of S6 downstream of mTORC1 depends on PLD activation, but is independent of mTORC2 and Akt signaling (Figure 6). During conditions where Erk1/2 signaling is inhibited, the initial S6 phosphorylation is delayed. Interfering with mTOR signaling did not affect PDGF-BB-induced Erk1/2 phosphorylation. Functionally, inhibition of mTORC1 and 2 by rapamycin effectively blocked PDGF-BB-mediated cell proliferation. Figure 6 depicts a schematic figure of key roles of mTOR in PDGF-BB-induced cell signaling.

\section{Materials and methods Reagents}

Recombinant human PDGF-BB was generously provided by Amgen (Thousand Oaks, CA). The inhibitors CI1040 (PD184352), triciribine and NVP-BKM120 were from Calbiochem (San Diego, CA), Cayman Chemical Company (Michigan, USA) and Selleckchem (Houston, USA), respectively. Antibodies against phosphorylated Akt (\#9271), phosphorylated mTOR (\#5536), phosphorylated S6 (\#4858), cleaved caspase 3 (\#9661), phosphorylated Erk1/2 (\#9106) and phospho-MARCKS (\#2741) were purchased from Cell Signaling Technology (Beverly, MA). A $\beta$-actin antibody was purchased from Sigma

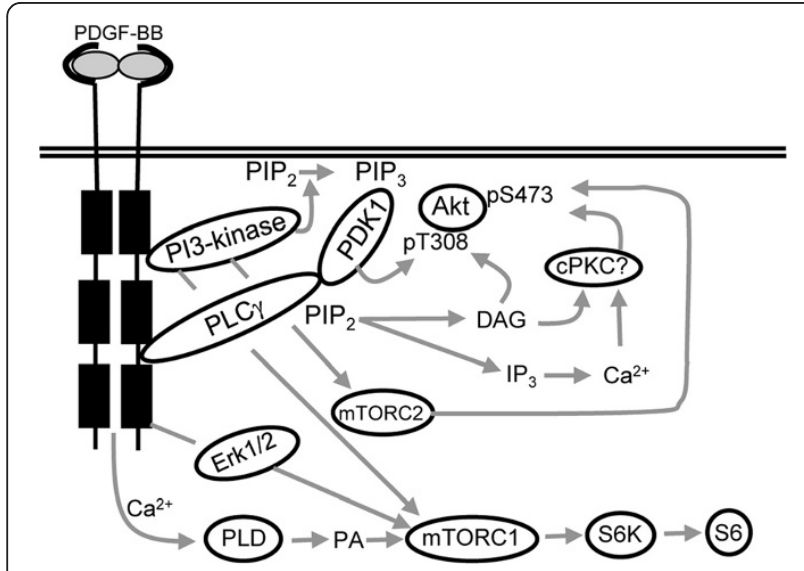

Figure 6 Schematic representation of PDGF-BB-mediated regulation of Akt and S6. Initially, PDGF-BB-mediated activation of Akt involves both mTORC2 and the PLCY/PKC pathways. Activation of $\mathrm{S} 6$ downstream of mTORC1 depends on PLD activation, independent of mTORC2 and Akt signaling. $\mathrm{Ca}^{2+}$ is required for regulation of Akt and $\mathrm{S} 6$ activity.
(St. Louis, MI). A rabbit antiserum recognizing Erk was raised against a peptide corresponding to the carboxylterminal sequence EETARFQPGYRS conjugated to KLH.

The wild-type control and Rictor-knockout mouse embryonic fibroblasts (MEFs) have been described previously [59] and were kindly provided by Dr Mark Magnuson (Vanderbilt University School of Medicine, Nashville, TN, U.S.A.). PLCY1-null MEFs have been described previously [70] and were kindly provided by Dr Matilda Katan (Institute for Cancer Research, London, UK).

\section{Cell culture}

The murine embryonic fibroblast cell line NIH3T3, and MEFs were cultured in Dulbecco's modified Eagle's medium (DMEM) with 10\% bovine serum, $100 \mathrm{U} / \mathrm{ml}$ penicillin and $100 \mu \mathrm{g} / \mathrm{ml}$ streptomycin. For serum-starvation, cells were washed once and incubated in medium containing $0.1 \%$ FBS. Lipase inactive PLC- $\gamma 1$ H335F/ H380F (dnPLC $)$, porcine aortic endothelial (PAE) cells were cultured in Ham's F-12 containing 10\% bovine serum albumin, in the presence or absence of $20 \mathrm{ng} / \mathrm{ml}$ doxycycline to induce protein expression [71].

\section{Immunoblotting}

Subconfluent cells were starved and incubated with vehicle or inhibitors at the indicated concentrations and thereafter stimulated with PDGF-BB $(20 \mathrm{ng} / \mathrm{ml}$, or as specified) for the indicated periods of time. Cells were washed two times in ice-cold phosphate-buffered saline and lysed in $20 \mathrm{mM}$ Tris $\mathrm{pH}$ 7.4, $150 \mathrm{mM} \mathrm{NaCl}, 5 \mathrm{mM}$ EDTA, 1\% Triton X-100, 0.1\% SDS, 1\% deoxycholate, $1 \mathrm{mM}$ Pefa Bloc and $1 \mathrm{mM}$ sodium orthovanadate. Extracts were clarified by centrifugation, and protein concentration was determined by the BCA protein assay (Pierce). Equal amounts of lysates were boiled with SDS sample buffer containing dithiothreitol. Proteins were separated by SDS-PAGE and then electro-transferred to polyvinylidene difluoride membranes (Immobilon P), which were blocked in $5 \%$ bovine serum albumin or $5 \%$ milk in Tris-buffered saline solution containing $0.1 \%$ Tween-20. Primary antibodies were diluted according to the manufacturer's instructions and membranes incubated overnight at $4^{\circ} \mathrm{C}$. After washing, the membranes were incubated with horseradish peroxidase-conjugated anti-rabbit or anti-mouse IgG antibodies (both from Amersham Biosciences), and proteins were visualized using ECL immunoblotting detection systems from Roche Applied Science on a cooled charge-coupled device (CCD) camera (Fuji, Minami-Ashigata, Japan). Densitometrical analysis of the immunoblots was performed using advanced image data analyzer (AIDA) software (Fujifilm). 


\section{Apoptosis assay}

Control and Rictor-null MEFs were starved for $24 \mathrm{~h}$, then the extent of apoptosis was determined by quantification of nucleosomes released into the cytoplasma using the Cell Death Detection ELISA Plus kit (Roche Applied Science) according to the manufacturer's directions. In the separate experiments the level of caspase3 -cleaved fragments was analyzed by immunoblotting.

\section{$\left[{ }^{3} \mathrm{H}\right]$ thymidine incorporation assay}

For thymidine incorporation assay subconfluent cell cultures were serum-starved in 24-well plates and then incubated for $24 \mathrm{~h}$ in the presence or absence of rapamycin with PDGF-BB in DMEM containing $\left[{ }^{3} \mathrm{H}\right]$ thymidine $(0.1 \mu \mathrm{Ci} / \mathrm{ml})$. Incorporation of ${ }^{3} \mathrm{H}$-radioactivity into acid-insoluble material was measured by a scintillation counter. The obtained count per minute values in triplicate was normalized against the positive control of cultures incubated in $10 \%$ bovine serum for each experiment.

\section{Cell migration assays}

Cell migration was determined as previously described [69]. In brief, 96-well ChemoTX (Neuroprobe, Gaithersburg, MD) cell migration microplate filters were coated with $50 \mu \mathrm{g} / \mathrm{ml}$ fibronectin (BD Biochemicals, Erembodegem, Belgium) for $1 \mathrm{~h}$ at room temperature. Control and Rictor null-MEFs, or NIH3T3 cells treated with or without rapamycin, were serum-starved overnight and then trypsinized into single cells. The wells of the ChemoTX microplate were filled with DMEM containing the indicated PDGF-BB concentrations. The filters were placed in the wells and 50,000 cells were added on top of each filter. The chamber was incubated for $4 \mathrm{~h}$ at $37^{\circ} \mathrm{C}, 5 \% \mathrm{CO}_{2}$. Cells adhering to the bottom of the filter were fixed by a 3-min incubation in $96 \%$ ethanol. The adherent cells were stained with Giemsa (Sigma)-and the migration indices were assessed by scanning the filter in a CCD camera (Fuji). Quantifications were performed using Aida Image Analyzer software. All experiments were performed in quadruplicate, and single representative data of three separate experiments \pm SD are shown.

\section{Abbreviations \\ Erk: Extracellular regulated kinase; MAPK: Mitogen activated protein kinase; MEF: Mouse embryo fibroblast; mTOR: Mammalian target of rapamycin; PDGF: Platelet-derived growth factor; PDGFR: PDGF receptor; PLCY1: Phospholipase C gamma 1; PI3K: Phosphatidylinositol 3-kinase.}

\section{Competing interests}

The authors declare that they have no competing interests.

\section{Authors' contributions}

MR, planned and performed experiments, analyzed the data and contributed to manuscript preparation; $\mathrm{CHH}$, planned experiments, analyzed data and contributed to manuscript preparation; $J$, planned and performed experiments, analyzed the data and contributed to manuscript preparation. All authors read and approved the final manuscript.

\section{Acknowledgements}

This work was supported by Ludwig Institute for Cancer Research, the Swedish Research

Council (K2011-67X-21859-01-6) and the Swedish Cancer Society (CAN 2009/657)

Received: 25 September 2012 Accepted: 9 January 2013

Published: 11 January 2013

\section{References}

1. Andrae J, Gallini R, Betsholtz C: Role of platelet-derived growth factors in physiology and medicine. Genes Dev 2008, 22:1276-1312.

2. Heldin $\mathrm{CH}$, Westermark B: Mechanism of action and in vivo role of platelet-derived growth factor. Physiol Rev 1999, 79:1283-1316.

3. Fredriksson L, Li H, Eriksson U: The PDGF family: four gene products form five dimeric isoforms. Cytokine Growth Factor Rev 2004, 15:197-204.

4. Sarbassov DD, Ali SM, Sabatini DM: Growing roles for the mTOR pathway. Curr Opin Cell Biol 2005, 17:596-603.

5. Bjornsti MA, Houghton PJ: The TOR pathway: a target for cancer therapy. Nat Rev Cancer 2004, 4:335-348.

6. Sawyers CL: Will mTOR inhibitors make it as cancer drugs?. Cancer Cell 2003, 4:343-348.

7. Bhaskar PT, Hay N: The two TORCs and Akt. Dev Cell 2007, 12:487-502.

8. Inoki K, Li Y, Zhu T, Wu J, Guan KL: TSC2 is phosphorylated and inhibited by Akt and suppresses mTOR signalling. Nat Cell Biol 2002, 4:648-657.

9. Manning BD, Tee AR, Logsdon MN, Blenis J, Cantley LC: Identification of the tuberous sclerosis complex-2 tumor suppressor gene product tuberin as a target of the phosphoinositide 3-kinase/akt pathway. Mol Cell 2002, 10:151-162.

10. Mamane $Y$, Petroulakis E, LeBacquer $O$, Sonenberg N: mTOR, translation initiation and cancer. Oncogene 2006, 25:6416-6422

11. Inoki K, Zhu T, Guan KL: TSC2 mediates cellular energy response to control cell growth and survival. Cell 2003, 115:577-590.

12. Kim DH, Sarbassov DD, Ali SM, King JE, Latek RR, Erdjument-Bromage $H_{\text {, }}$ Tempst $P$, Sabatini DM: mTOR interacts with raptor to form a nutrientsensitive complex that signals to the cell growth machinery. Cell 2002, 110:163-175.

13. Hay N, Sonenberg N: Upstream and downstream of mTOR. Genes Dev 2004, 18:1926-1945.

14. Frias MA, Thoreen CC, Jaffe JD, Schroder W, Sculley T, Carr SA, Sabatini DM: $\mathrm{mSin} 1$ is necessary for Akt/PKB phosphorylation, and its isoforms define three distinct mTORC2s. Curr Biol 2006, 16:1865-1870.

15. Pearce $L R$, Huang $X$, Boudeau J, Pawlowski $R$, Wullschleger $S$, Deak M, Ibrahim AF, Gourlay R, Magnuson MA, Alessi DR: Identification of Protor as a novel Rictor-binding component of mTOR complex-2. Biochem J 2007, 405:513-522.

16. Martin J, Masri J, Bernath A, Nishimura RN, Gera J: Hsp70 associates with Rictor and is required for mTORC2 formation and activity. Biochem Biophys Res Commun 2008, 372:578-583.

17. Populo H, Lopes JM, Soares P: The mTOR Signalling Pathway in Human Cancer. Int J Mol Sci 2012, 13:1886-1918.

18. Dalle Pezze P, Sonntag AG, Thien A, Prentzell MT, Godel M, Fischer S, Neumann-Haefelin E, Huber TB, Baumeister R, Shanley DP, Thedieck K: A dynamic network model of mTOR signaling reveals TSC-independent mTORC2 regulation. Sci Signal 2012, 5:ra25.

19. Sarbassov DD, Guertin DA, Ali SM, Sabatini DM: Phosphorylation and regulation of Akt/PKB by the rictor-mTOR complex. Science 2005, 307:1098-1101.

20. Sarbassov DD, Ali SM, Kim DH, Guertin DA, Latek RR, Erdjument-Bromage H, Tempst P, Sabatini DM: Rictor, a novel binding partner of $\mathrm{mTOR}$, defines a rapamycin-insensitive and raptor-independent pathway that regulates the cytoskeleton. Curr Biol 2004, 14:1296-1302.

21. Alessi DR, James SR, Downes CP, Holmes AB, Gaffney PR, Reese CB, Cohen $P$ : Characterization of a 3-phosphoinositide-dependent protein kinase which phosphorylates and activates protein kinase Balpha. Curr Biol 1997, 7:261-269

22. Stokoe D, Stephens LR, Copeland T, Gaffney PR, Reese CB, Painter GF, Holmes AB, McCormick F, Hawkins PT: Dual role of phosphatidylinositol-3,4,5-trisphosphate in the activation of protein kinase B. Science 1997, 277:567-570.

23. Feng J, Park J, Cron P, Hess D, Hemmings BA: Identification of a PKB/Akt hydrophobic motif Ser-473 kinase as DNA-dependent protein kinase. J Biol Chem 2004, 279:41189-41196. 
24. Bozulic L, Surucu B, Hynx D, Hemmings BA: PKBalpha/Akt1 acts downstream of DNA-PK in the DNA double-strand break response and promotes survival. Mol Cell 2008, 30:203-213.

25. Persad S, Attwell S, Gray V, Mawji N, Deng JT, Leung D, Yan J, Sanghera J, Walsh MP, Dedhar S: Regulation of protein kinase B/Akt-serine 473 phosphorylation by integrin-linked kinase: critical roles for kinase activity and amino acids arginine 211 and serine 343. J Biol Chem 2001, 276:27462-27469.

26. Greer $E L$, Brunet $A$ : FOXO transcription factors at the interface between longevity and tumor suppression. Oncogene 2005, 24:7410-7425.

27. Datta SR, Dudek H, Tao X, Masters S, Fu H, Gotoh Y, Greenberg ME: Akt phosphorylation of BAD couples survival signals to the cell-intrinsic death machinery. Cell 1997, 91:231-241.

28. Cardone MH, Roy N, Stennicke HR, Salvesen GS, Franke TF, Stanbridge E, Frisch S, Reed JC: Regulation of cell death protease caspase- 9 by phosphorylation. Science 1998, 282:1318-1321.

29. Rebecchi MJ, Pentyala SN: Structure, function, and control of phosphoinositide-specific phospholipase C. Physiol Rev 2000, 80:1291-1335.

30. Mellor H, Parker PJ: The extended protein kinase C superfamily. Biochem J 1998, 332(Pt 2):281-292.

31. Nishizuka Y: Protein kinase $C$ and lipid signaling for sustained cellular responses. FASEB J 1995, 9:484-496.

32. Sierke SL, Koland JG: SH2 domain proteins as high-affinity receptor tyrosine kinase substrates. Biochemistry 1993, 32:10102-10108.

33. Heldin $\mathrm{CH}$, Ostman A, Ronnstrand L: Signal transduction via platelet-derived growth factor receptors. Biochim Biophys Acta 1998, 1378:F79-F113.

34. Exton JH: Regulation of phospholipase D. Biochim Biophys Acta 1999 1439:121-133.

35. Fang $Y$, Vilella-Bach M, Bachmann R, Flanigan A, Chen J: Phosphatidic acidmediated mitogenic activation of mTOR signaling. Science 2001, 294:1942-1945.

36. Vorland $M$, Thorsen VA, Holmsen H: Phospholipase D in platelets and other cells. Platelets 2008, 19:582-594

37. Min DS, Kim EG, Exton JH: Involvement of tyrosine phosphorylation and protein kinase $C$ in the activation of phospholipase $D$ by $\mathrm{H}_{2} \mathrm{O} 2$ in Swiss 3T3 fibroblasts. J Biol Chem 1998, 273:29986-29994.

38. Maira SM, Pecchi S, Huang A, Burger M, Knapp M, Sterker D, Schnell C, Guthy $D$, Nagel T, Wiesmann $M$, et al: Identification and characterization of NVP-BKM120, an orally available pan-class I PI3-kinase inhibitor. Mol Cancer Ther 2011, 11:317-328.

39. Sarbassov DD, Ali SM, Sengupta S, Sheen JH, Hsu PP, Bagley AF, Markhard $\mathrm{AL}$, Sabatini DM: Prolonged rapamycin treatment inhibits mTORC2 assembly and Akt/PKB. Mol Cell 2006, 22:159-168.

40. Gingras AC, Kennedy SG, O'Leary MA, Sonenberg N, Hay N: 4E-BP1, a repressor of mRNA translation, is phosphorylated and inactivated by the Akt(PKB) signaling pathway. Genes Dev 1998, 12:502-513.

41. Lizcano JM, Alrubaie S, Kieloch A, Deak M, Leevers SJ, Alessi DR: Insulin-induced Drosophila S6 kinase activation requires phosphoinositide 3-kinase and protein kinase B. Biochem J 2003, 374:297-306

42. Miron M, Lasko P, Sonenberg N: Signaling from Akt to FRAP/TOR targets both 4E-BP and S6K in Drosophila melanogaster. Mol Cell Biol 2003, 23:9117-9126.

43. Yang L, Dan HC, Sun M, Liu Q, Sun XM, Feldman RI, Hamilton AD, Polokoff $M$, Nicosia SV, Herlyn $M$, et al: Akt/protein kinase B signaling inhibitor-2, a selective small molecule inhibitor of Akt signaling with antitumor activity in cancer cells overexpressing Akt. Cancer Res 2004, 64:4394-4399.

44. Morris AJ, Frohman MA, Engebrecht J: Measurement of phospholipase D activity. Anal Biochem 1997, 252:1-9.

45. Clunn GF, Lymn JS, Schachter M, Hughes AD: Differential effects of lovastatin on mitogen induced calcium influx in human cultured vascular smooth muscle cells. Br J Pharmacol 1997, 121:1789-1795.

46. Huang R, Kucera GL, Rittenhouse SE: Elevated cytosolic Ca2+ activates phospholipase D in human platelets. J Biol Chem 1991, 266:1652-1655.

47. Hu T, Liu Z, Shen X: Roles of phospholipase D in phorbol myristate acetatestimulated neutrophil respiratory burst. J Cell Mol Med 2011, 15:647-653.

48. Burgdorf C, Schafer U, Richardt G, Kurz T: U73122, an aminosteroid phospholipase $C$ inhibitor, is a potent inhibitor of cardiac phospholipase D by a PIP2-dependent mechanism. J Cardiovasc Pharmacol 2010, 55:555-559.

49. Hess JA, Ji QS, Carpenter G, Exton JH: Analysis of platelet-derived growth factor-induced phospholipase $D$ activation in mouse embryo fibroblasts lacking phospholipase C-gamma1. J Bio/ Chem 1998, 273:20517-20524.
50. Rane MJ, Coxon PY, Powell DW, Webster R, Klein JB, Pierce W, Ping P, McLeish KR: p38 Kinase-dependent MAPKAPK-2 activation functions as 3-phosphoinositide-dependent kinase-2 for Akt in human neutrophils. J Biol Chem 2001, 276:3517-3523.

51. Guertin DA, Stevens DM, Thoreen CC, Burds AA, Kalaany NY, Moffat J, Brown $M$, Fitzgerald KJ, Sabatini DM: Ablation in mice of the mTORC components raptor, rictor, or $\mathrm{mLST} 8$ reveals that $\mathrm{mTORC2}$ is required for signaling to Akt-FOXO and PKCalpha, but not S6K1. Dev Cell 2006, 11:859-871.

52. Kim HK, Kim JW, Zilberstein A, Margolis B, Kim JG, Schlessinger J, Rhee SG: PDGF stimulation of inositol phospholipid hydrolysis requires PLC-gamma 1 phosphorylation on tyrosine residues 783 and 1254. Cell 1991, 65:435-441.

53. Ikenoue T, Inoki K, Yang Q, Zhou X, Guan KL: Essential function of TORC2 in PKC and Akt turn motif phosphorylation, maturation and signalling. EMBO J 2008, 27:1919-1931.

54. Chiang GG, Abraham RT: Targeting the mTOR signaling network in cancer. Trends Mol Med 2007, 13:433-442.

55. Riaz A, Zeller KS, Johansson S: Receptor-specific mechanisms regulate phosphorylation of AKT at Ser473: role of RICTOR in beta1 integrinmediated cell survival. PLoS One 2012, 7:e32081.

56. Dong LQ, Liu F: PDK2: the missing piece in the receptor tyrosine kinase signaling pathway puzzle. Am J Physiol Endocrinol Metab 2005, 289:E187-E196.

57. Raimondi C, Chikh A, Wheeler AP, Maffucci T, Falasca M: A novel regulatory mechanism links PLCY1 to PDK1. J Cell Sci 2012, 125:3153-3163.

58. Brazil DP, Yang ZZ, Hemmings BA: Advances in protein kinase $B$ signalling: AKTion on multiple fronts. Trends Biochem Sci 2004, 29:233-242.

59. Shiota C, Woo JT, Lindner J, Shelton KD, Magnuson MA: Multiallelic disruption of the rictor gene in mice reveals that mTOR complex 2 is essential for fetal growth and viability. Dev Cell 2006, 11:583-589.

60. Dong J, Pan D: Tsc2 is not a critical target of Akt during normal Drosophila development. Genes Dev 2004, 18:2479-2484.

61. El Kirat K, Besson F, Prigent AF, Chauvet JP, Roux B: Role of calcium and membrane organization on phospholipase $D$ localization and activity Competition between a soluble and insoluble substrate. J Biol Chem 2002, 277:21231-21236.

62. Pullen N, Dennis PB, Andjelkovic M, Dufner A, Kozma SC, Hemmings BA Thomas G: Phosphorylation and activation of p70s6k by PDK1. Science 1998, 279:707-710.

63. Roux PP, Blenis J: ERK and p38 MAPK-activated protein kinases: a family of protein kinases with diverse biological functions. Microbiol Mol Biol Rev 2004, 68:320-344.

64. Carriere A, Romeo Y, Acosta-Jaquez HA, Moreau J, Bonneil E, Thibault P, Fingar DC, Roux PP: ERK1/2 phosphorylate Raptor to promote Ras-dependent activation of mTOR complex 1 (mTORC1). J Biol Chem 2010, 286:567-577.

65. Magnuson B, Ekim B, Fingar DC: Regulation and function of ribosomal protein S6 kinase (S6K) within mTOR signalling networks. Biochem J 2012, 441:1-21.

66. Albert L, Karsy M, Murali R, Jhanwar-Uniyal M: Inhibition of mTOR Activates the MAPK Pathway in Glioblastoma Multiforme. Cancer Genomics Proteomics 2009, 6:255-261.

67. Liu L, Parent CA: Review series: TOR kinase complexes and cell migration. J Cell Biol 2011, 194:815-824.

68. Liu L, Das S, Losert W, Parent CA: mTORC2 regulates neutrophil chemotaxis in a CAMP- and RhoA-dependent fashion. Dev Cell 2010, 19:845-857.

69. Amagasaki $\mathrm{K}$, Kaneto $\mathrm{H}$, Heldin $\mathrm{CH}$, Lennartsson J: c-Jun N-terminal kinase is necessary for platelet-derived growth factor-mediated chemotaxis in primary fibroblasts. J Biol Chem 2006, 281:22173-22179.

70. Ji QS, Ermini S, Baulida J, Sun FL, Carpenter G: Epidermal growth factor signaling and mitogenesis in Plcg1 null mouse embryonic fibroblasts. Mol Biol Cell 1998, 9:749-757.

71. Ronnstrand L, Siegbahn A, Rorsman C, Johnell M, Hansen K, Heldin CH: Overactivation of phospholipase C-gamma1 renders platelet-derived growth factor beta-receptor-expressing cells independent of the phosphatidylinositol 3-kinase pathway for chemotaxis. J Biol Chem 1999 274:22089-22094

doi:10.1186/1478-811X-11-3

Cite this article as: Razmara et al:: Platelet-derived growth factorinduced Akt phosphorylation requires $\mathrm{mTOR} /$ Rictor and phospholipase C- $\gamma$ 1, whereas S6 phosphorylation depends on mTOR/Raptor and phospholipase D. Cell Communication and Signaling 2013 11:3. 